\title{
Sex-biased differences in the effects of host individual, host population and environmental traits driving tick parasitism in red deer
}

\author{
Francisco Ruiz-Fons ${ }^{1 *}{ }^{\dagger}$, Pelayo Acevedo ${ }^{2+}{ }^{,}$Raquel Sobrino ${ }^{1}$, Joaquín Vicente ${ }^{1}$, Yolanda Fierro ${ }^{3}$ and \\ Isabel G. Fernández-de-Mera ${ }^{1,4}$ \\ ' Animal Health and Biotechnology Group (SaBio), Spanish National Wildlife Research Institute (IREC, CSIC-UCLM-JCCM), Ciudad Real, Spain \\ ${ }^{2}$ Conservation Genetics and Wildlife Management Department, InBio Laboratório Associado, CIBIO, Centro de Investigação em Biodiversidade e Recursos \\ Genéticos, Universidade do Porto, Vairão, Portugal \\ ${ }^{3}$ Yolfi Properties, Ciudad Real, Spain \\ ${ }^{4}$ Centro de Vigilancia Sanitaria Veterinaria (VISAVET), Departamento de Sanidad Animal, Universidad Complutense de Madrid, Madrid, Spain
}

\section{Edited by:}

Agustín Estrada-Peña, University of

Zaragoza, Spain

\section{Reviewed by:}

Dongsheng Zhou, Beijing Institute of

Microbiology and Epidemiology,

China

Christian Kiffner, The School For

Field Studies, Tanzania

\section{*Correspondence:}

Francisco Ruiz-Fons, Animal Health and Biotechnology Group (SaBio), Spanish National Wildlife Research Institute (IREC), Ronda de Toledo $s / n$, Ciudad Real 13071, Spain e-mail: josefrancisco.ruiz@uclm.es

these authors have contributed equally to this work.
The interactions between host individual, host population, and environmental factors modulate parasite abundance in a given host population. Since adult exophilic ticks are highly aggregated in red deer (Cervus elaphus) and this ungulate exhibits significant sexual size dimorphism, life history traits and segregation, we hypothesized that tick parasitism on males and hinds would be differentially influenced by each of these factors. To test the hypothesis, ticks from 306 red deer-182 males and 124 females-were collected during 7 years in a red deer population in south-central Spain. By using generalized linear models, with a negative binomial error distribution and a logarithmic link function, we modeled tick abundance on deer with 20 potential predictors. Three models were developed: one for red deer males, another for hinds, and one combining data for males and females and including "sex" as factor. Our rationale was that if tick burdens on males and hinds relate to the explanatory factors in a differential way, it is not possible to precisely and accurately predict the tick burden on one sex using the model fitted on the other sex, or with the model that combines data from both sexes. Our results showed that deer males were the primary target for ticks, the weight of each factor differed between sexes, and each sex specific model was not able to accurately predict burdens on the animals of the other sex. That is, results support for sex-biased differences. The higher weight of host individual and population factors in the model for males show that intrinsic deer factors more strongly explain tick burden than environmental host-seeking tick abundance. In contrast, environmental variables predominated in the models explaining tick burdens in hinds.

Keywords: host-parasite, polygynous, cervidae, tick, sexual segregation

\section{INTRODUCTION}

Tick distribution in their hosts is frequently found to be highly aggregated in a few individuals within the host population, which determines that a few hosts are responsible for feeding large amounts of ticks (Shaw and Dobson, 1995; Shaw et al., 1998). This ecological feature of tick-host interactions greatly conditions the transmission of pathogens between ticks and their hosts (Perkins et al., 2003). The probability of tick-borne pathogen transmission at the tick-host interface largely depends on the burden of ticks feeding in a single infected individual, especially when cofeeding transmission is of great relevance for the epidemiology of the pathogen (Perkins et al., 2003). Thus, identifying factors driving tick-host relationships in each tick-host system is crucial to both prevent undesired effects on target and accidental hosts that may be highly susceptible to certain tick-borne pathogens and to reduce risks of transmission to humans of zoonotic pathogens.

Higher individual macroparasite burdens would be expected to be associated with lower immune capacity to fight against parasites (Vicente et al., 2007a), though recent studies link higher macroparasite burdens to host activity traits (Boyer et al., 2010), body mass (Kiffner et al., 2013) or to other effects linked to tick distribution in the environment (Calabrese et al., 2011). Since exophilic ticks are highly aggregated in the environment (Ruiz-Fons and Gilbert, 2010), the rate of host-tick effective contacts at a local spatial scale would consequently be expected to be higher for hosts displaying higher activity and higher body surface. However, many studies have dealt with the immunocompetence handicap hypothesis (Folstad and Karter, 1992) driving the burden of macroparasites in their hosts (Hughes and Randolph, 2001; Malo et al., 2009). The immunocompetence handicap hypothesis basically proposes that testosterone has a dual effect on males, enhancing expression of secondary sexual traits and depressing the immune system. Thus, better males could allow overexpression of sexual traits while overcoming negative effects related to immunocompetence reduction. Therefore, physical (morphology), ecological (behavior), and physiological 
(testosterone levels) factors have been considered as main drivers of parasitism in mammals (Moore and Wilson, 2002; Alzaga et al., 2009; Kiffner et al., 2013).

Sex-biased parasitism has been reported in many different host-parasite systems, often displaying a male-biased parasitism in highly dimorphic species (Moore and Wilson, 2002; Kiffner et al., 2013), especially those subjected to greater intraspecific competition for resources (Bacelar et al., 2011). Resource partitioning in self-maintenance, reproduction and defense against parasites is the result of a basic trade-off experienced by animals (Clutton-Brock et al., 1982). Mating system in polygynous mammals may carry over drastic resource allocation changes in individuals, especially in males, whose priorities in mating are more important than those related to immunocompetence (Rolff, 2002). Red deer (Cervus elaphus) males display a "live hard, die young" strategy (Carranza et al., 2004) in contrast to females that tend to allocate resources to self-maintenance, offspring rearing, and immunity, which has been deemed as one of the main sexual behavioral traits enhancing higher parasite loads in male red deer (Vicente et al., 2007a,b). Sex-related effects on tick burdens in mammals are controversial. Several authors described a clear sex-related effect on tick burden in white-tailed deer (Odocoileus virginianus; Schulze et al., 1984; Kitron et al., 1992; Schmidtmann et al., 1998), while recent studies in German roe deer (Capreolus capreolus) found no sexrelated effect on tick burdens (Vor et al., 2010; Kiffner et al., 2011). The latter authors assume these host-species related differences in wild ruminants could be linked to sexual dimorphism, since dimorphism is higher in white-tailed than in roe deer, but it also could be linked to other factors related to sexual segregation.

Since adult exophilic ticks are highly aggregated in red deer and this wild ruminant exhibits a significant sexual size, resource allocation in immunity and behavioral dimorphism (e.g., CluttonBrock et al., 1982), we hypothesized that parasitism by ticks-i.e., tick abundance on hosts-on each sex would be differentially influenced by host individual, host population and environmental factors. Predicting tick burdens in hinds with factors identified to drive tick burdens in males, and vice-versa, could be accurate only in the case of factors having the same weight on parasite burdens in both sexes. Otherwise, prediction of tick burdens, and hence identification of key hosts for tick-borne pathogens, would need to differentially consider host sex.

\section{MATERIALS AND METHODS STUDY AREA AND HOST INDIVIDUAL TRAITS}

The study area comprised a 900 ha hunting estate located in Ciudad Real province (south-central Spain: $38^{\circ} 55^{\prime} \mathrm{N}, 0^{\circ} 36^{\prime} \mathrm{E}$; $600-850 \mathrm{~m}$ a. s. 1.) of which 700 ha are dedicated to game rearing for hunting purposes, mostly Iberian red deer (C. elaphus hispanicus) and Eurasian wild boar (Sus scrofa) but also small numbers of mouflon (Ovis aries musimon) and aoudad (Ammotragus lervia). Orography in the estate is formed by hill chains (up to $100 \mathrm{~m}$ high) bordering three main valleys. Hills are covered by Mediterranean shrub ecosystem composed by scattered Quercus ilex trees and shrub dominated by Cystus spp. Pistacia spp., Rosmarinus spp., Erica spp., Arbutus unedo, and
Phyllirea spp. Valleys are dedicated to grow seasonal cereal crops for game feeding. Climate is continental Mediterranean with cold winters and very hot and dry summers and rainfall-ranging 300-700 mm annually — is highly seasonal. Supplementary food (mixed cereal-leguminous pellets) is available ad-libitum along the year for deer on selective feeders located at the bottom of valleys ( 8 feeding points). Additionally, water supply is maintained all-over the year in eight water ponds distributed along riverbeds in valleys.

Over 7 years, from 2004 to 2010, hunter harvested red deer were surveyed for ticks immediately after being shot. The whole deer body was surveyed for ticks, which were counted and collected. Every tick from lowly parasitized animals ( $<30$ ticks) was collected while a representative subsample of ticks were collected in highly parasitized individuals ( $>30$ ticks). Every immature stage located was collected from deer carcasses. Collected ticks were identified to species level (Manilla, 1998; Estrada-Peña et al., 2004; Apanaskevich and Horak, 2008; Apanaskevich et al., 2008).

Every deer surveyed was subjected to a detailed necropsy to detect any lesion caused by macro or microparasites (e.g., tuberculosis-like lesions; see Vicente et al., 2006) in different organs, weighed, sexed, and biometrically characterized-total length, hind foot length, and thoracic perimeter (measured to the nearest $0.1 \mathrm{~cm}$ ). During necropsies, spleen was weighed to the nearest $0.1 \mathrm{~g}$ and kidney fat index (KFI) was calculated as an estimation of body fat (Santos et al., 2013). Age was determined for young individuals ( $<2$ years old) based on tooth eruption patterns (Sáenz de Buruaga et al., 1991) and by incisor 1 sectioning in $>2$ year old animals (Klevezal and Kleinenberg, 1967). Deer age was categorized into 5 classes: (1) fawns (0-1 year old); (2) yearlings ( $1-2$ years old); (3) subadults ( $2-3$ years old); (4) adults (4-10 years old); and (5) old ( $>10$ years old). Maximum recorded age was 23 years. Individual host data throughout sex and age class is shown in Table $\mathbf{1}$.

\section{HOST POPULATION TRAITS}

Host abundance is a key factor influencing host-seeking tick burdens in the environment at local geographic scales that could greatly condition tick burden in individual hosts (Ruiz-Fons et al., 2012). At the short time-scale (i.e., a year) the influence of host abundance on tick environmental abundance is difficult to measure since individual ticks may take up to several years to complete their life cycle. However, at the long-time scale changes in key host availability between years may be reflected in changes in hostseeking tick abundance. Wild ungulates are key hosts for adults of the predominant tick species in the estate (Hyalomma lusitanicum and Rhipicephalus bursa; see Ruiz-Fons et al., 2006) so annual censuses for the most abundant ungulate species in the estate, that is, red deer and wild boar, were used as predictors for tick burden models. The effect of host abundance in previous years on current tick burdens was tested by considering deer and wild boar abundance in years $t-1$ and $t-2$ (see Ostfeld et al., 2006). Censuses were performed by experienced observers (gamekeepers) who counted individuals approaching feeders at the bottom of the valleys (total counts) during the red deer rut season. For further details on the census procedure see Rodríguez-Hidalgo et al. (2010). 


\section{ENVIRONMENTAL VARIABLES}

Climatic conditions (e.g., temperature and hydric stress) greatly condition tick phenology, activity, and survival (Estrada-Peña et al., 2011). Adult tick burden in an individual host at a given

Table 1 | Average values, associated standard error and range (within brackets) of host individual variables [total length ( $\mathrm{TL} ; \mathrm{cms}$ ), thoracic perimeter (TP; cms), hind foot length (HF; cms), and kidney fat index $(\mathrm{KFI} ; \%)]$ throughout sex and age class of studied deer.

\begin{tabular}{|c|c|c|c|c|c|}
\hline Sex & $\begin{array}{l}\text { Age } \\
\text { class }\end{array}$ & TL & TP & HF & KFI \\
\hline \multirow[t]{6}{*}{ Male } & Fawn & $\begin{array}{l}133.8 \pm 2.7 \\
(104-149)\end{array}$ & $\begin{array}{l}93.4 \pm 2.6 \\
(68-115)\end{array}$ & $\begin{array}{l}45.3 \pm 0.9 \\
(34-51)\end{array}$ & $\begin{array}{l}88.0 \pm 21.3 \\
(9.5-385.5)\end{array}$ \\
\hline & Yearling & $\begin{array}{l}165.8 \pm 1.3 \\
(149-178)\end{array}$ & $\begin{array}{l}115.0 \pm 1.9 \\
(101-132)\end{array}$ & $\begin{array}{l}51.8 \pm 0.4 \\
(48-56)\end{array}$ & $\begin{array}{l}4.3 \pm 6.4 \\
(4.6-107.7)\end{array}$ \\
\hline & Subadult & $\begin{array}{l}174.9 \pm 2.4 \\
(161-187)\end{array}$ & $\begin{array}{l}115.9 \pm 1.7 \\
(108-127)\end{array}$ & $\begin{array}{l}53.1 \pm 1.7 \\
(49-62)\end{array}$ & $\begin{array}{l}41.6 \pm 7.8 \\
(15.2-85.6)\end{array}$ \\
\hline & Adult & $\begin{array}{l}187.7 \pm 1.1 \\
(158-213)\end{array}$ & $\begin{array}{l}125.8 \pm 0.7 \\
(111-155)\end{array}$ & $\begin{array}{l}53.3 \pm 0.2 \\
(48-61)\end{array}$ & $\begin{array}{l}65.7 \pm 8.5 \\
(4.9-455.3)\end{array}$ \\
\hline & Old & $\begin{array}{l}188.8 \pm 2.6 \\
(174-203)\end{array}$ & $\begin{array}{l}125.0 \pm 1.9 \\
(116-134)\end{array}$ & $\begin{array}{l}52.8 \pm 0.7 \\
(49-56)\end{array}$ & $\begin{array}{l}48.9 \pm 14.0 \\
(7.5-106.4)\end{array}$ \\
\hline & $\begin{array}{l}\text { Subtotal } \\
\text { male }\end{array}$ & $\begin{array}{l}178.1 \pm 1.5 \\
(104-213)\end{array}$ & $\begin{array}{l}120.2 \pm 1.0 \\
(68-155)\end{array}$ & $\begin{array}{l}52.2 \pm 0.3 \\
(34-62)\end{array}$ & $\begin{array}{l}63.0 \pm 6.5 \\
(4.6-455.3)\end{array}$ \\
\hline \multirow[t]{6}{*}{ Female } & Fawn & $\begin{array}{l}128.5 \pm 3.5 \\
(95-152)\end{array}$ & $\begin{array}{l}86.1 \pm 2.6 \\
(64-106)\end{array}$ & $\begin{array}{l}44.3 \pm 0.8 \\
(35-49)\end{array}$ & $\begin{array}{l}78.0 \pm 19.3 \\
(7.4-247.0)\end{array}$ \\
\hline & Yearling & $\begin{array}{l}148.4 \pm 2.9 \\
(130-161)\end{array}$ & $\begin{array}{l}108.0 \pm 6.5 \\
(88-162)\end{array}$ & $\begin{array}{l}49.1 \pm 0.7 \\
(45-53)\end{array}$ & $\begin{array}{l}122.2 \pm 23.2 \\
(61.0-241.0)\end{array}$ \\
\hline & Subadult & $\begin{array}{l}160.6 \pm 2.3 \\
(147-174)\end{array}$ & $\begin{array}{l}105.2 \pm 2.0 \\
(91-114)\end{array}$ & $\begin{array}{l}49.3 \pm 0.3 \\
(47-51)\end{array}$ & $\begin{array}{l}74.7 \pm 17.6 \\
(20.0-232.0)\end{array}$ \\
\hline & Adult & $\begin{array}{l}162.4 \pm 1.1 \\
(133-184)\end{array}$ & $\begin{array}{l}110.3 \pm 0.9 \\
(89-130)\end{array}$ & $\begin{array}{l}48.7 \pm 0.2 \\
(43-53)\end{array}$ & $\begin{array}{l}93.8 \pm 8.4 \\
(2.4-263.5)\end{array}$ \\
\hline & Old & $\begin{array}{l}166.6 \pm 1.7 \\
(160-178)\end{array}$ & $\begin{array}{l}110.2 \pm 1.7 \\
(104-120)\end{array}$ & $\begin{array}{l}48.7 \pm 0.4 \\
(47-51)\end{array}$ & $\begin{array}{l}119.7 \pm 25.0 \\
(30.9-283.9)\end{array}$ \\
\hline & $\begin{array}{l}\text { Subtotal } \\
\text { female }\end{array}$ & $\begin{array}{l}157.2 \pm 1.3 \\
(95-184)\end{array}$ & $\begin{array}{l}106.0 \pm 1.0 \\
(64-130)\end{array}$ & $\begin{array}{l}48.2 \pm 0.2 \\
(35-53)\end{array}$ & $\begin{array}{l}94.4 \pm 6.6 \\
(2.4-283.9)\end{array}$ \\
\hline
\end{tabular}

time is a function of the ticks encountered by the individual within a two week period since this is the average time adult Hyalomma ticks remain feeding in their host (Estrada-Peña et al., 2011). Thus, meteorological data at the short time scale, i.e., in 30 days before each animal was surveyed, were considered as a proxy of climatic constraints of tick activity. Considering a 30 days period aimed to buffer the occurrence of any stochastic meteorological event that could have momentarily affected tick questing behavior and consequently tick burdens on hosts. Meteorological data-temperature and precipitation-on a daily basis were obtained from a meteorological station (Spanish Meteorological Agency reference station 4210E; http://www.aemet.es) located in the study hunting estate (Table 2). The actual evapotranspiration (AET) - a measure of hydric stress experienced by ticks in its off-host period-was calculated on the basis of temperature and precipitation data using the formula proposed by Turc (1954), as follows:

$$
\mathrm{AET}=\frac{P}{\sqrt{0.9}+\left(\frac{P^{2}}{L^{2}}\right)}
$$

where " $P$ " is accumulated precipitation in $\mathrm{mm}$ and " $L$ " is defined by:

$$
L=300 \times 25 t+0.05 t^{3}
$$

being " $t$ " the mean temperature in ${ }^{\circ} \mathrm{C}$.

\section{STATISTICAL MODELLING AND ANALYTICAL DESIGN}

For descriptive analyses of parasitization rates the statistical uncertainty was assessed by calculating the $95 \%$ confidence interval for each of the proportions according to the expression $95 \%$ C.I. $=1.96[p(1-p) / n]^{1 / 2}$ (where " $p$ " is the proportion in its unitary value and " $n$ " is the sample size) and expressed in percentage.

Using an inductive approach we quantified the effect of the main factors able to explain tick burdens on red deer, at individual level. Predictors were considered in generalized linear models

Table 2 | Deer, wild boar, total ungulate (deer + boar + mouflon + aoudad) counts, and average values of climatic variables (and associated standard error within brackets) associated to deer sampling date in the hunting estate throughout year.

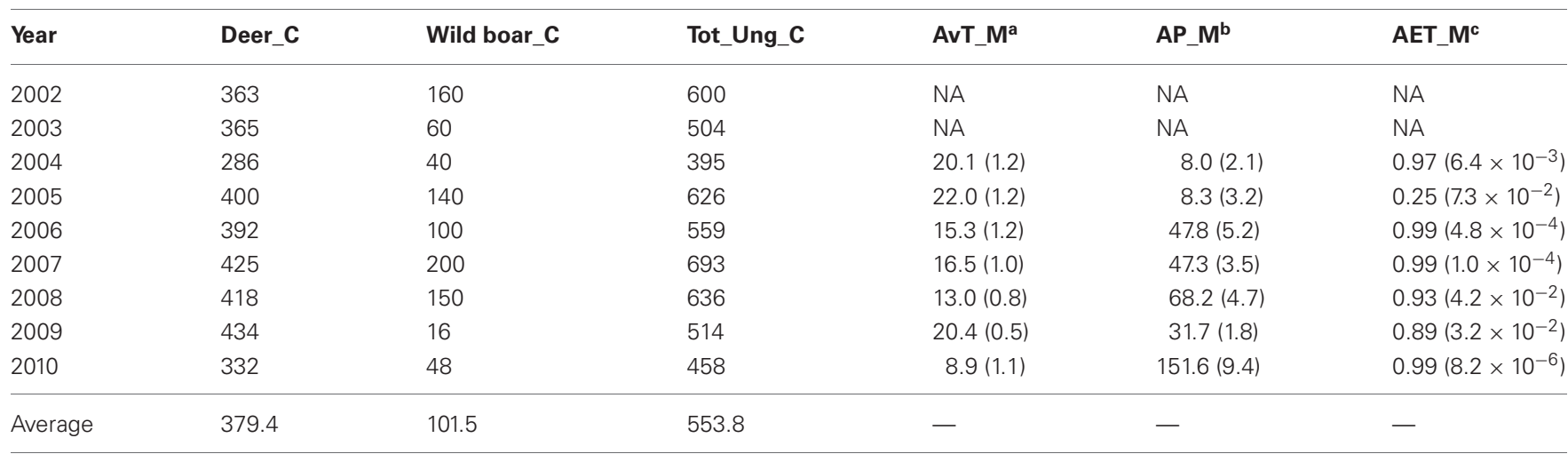

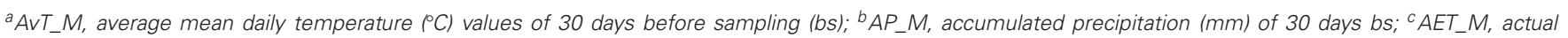
evapotranspiration ( $\mathrm{mm}$ ) of 30 days bs. NA, Not applicable. 
with a negative binomial distribution and a logarithmic link function (Cameron and Trivedi, 1998), and the final models (three, see below) were obtained using a forwards-backwards stepwise procedure based on Akaike Information Criteria (AIC; Akaike, 1974). We opted for the negative binomial distribution due to high levels of overdispersion in the data when models were fitted with Poisson distributions. The multicolineality among predictors included in the final models was assessed using predictor's variance inflation factor (VIF). VIFs were calculated-for each predictor and model-as the inverse of the coefficient of nondetermination for a regression of a given predictor on all others (see Zuur et al., 2010).

Because we were interested if tick-burdens were affected differentially in male and female deer, we developed three models: a model for red deer males, a model for hinds, and, finally, a model combining data for males and hinds and including "sex" as factor. If parasitization by ticks on red deer males and hinds responded to the explanatory factors in a differential way, it would be not possible to precisely and accurately predict the tick burden on hinds using the model fitted on males (and/or vice-versa), or with the model that combines data for males and hinds. However, if parasite loads on males and hinds similarly responded to the explanatory factors, then any of the independent models could precisely determine the rates of either sex, and in this occasion better adjust terms and more accurate predictions could be attained with the model carried out by combining data from males and hinds than with the independent model for each sex. Two analytical procedures were used in order to compare the model in the previous terms: variation partitioning and cross-validation.

Variation partitioning procedures (see Borcard et al., 1992) were used to estimate the variation of the final models explained independently by each factor (pure effects) and the variation explained simultaneously by two or more factors (overlaid effects; see Figure A1). Note that a factor is a group of related-predictors; in this study three factors: individual host, host population and environment. For this purpose, we determined the total amount of deviance explained by the final model. Subsequently, we developed the partial models, i.e., models adjusted independently with the predictors related to each factor (individual host: Ind, host population: Pop, and environment: Env), as well as with those of each pair of factors (Ind + Pop, Ind + Env, and Pop + Env), and estimated the amounts of deviance explained by each of these six partial models. Values of the deviance explained by the final model (Ind + Pop + Env) and those explained by the partial models were subjected to subtraction rules in order to split up the different sections of the explained variation (see Alzaga et al., 2009). A complete scheme of each part of deviance and the subtraction rules used for their determination, is reported in Appendix. Briefly, the proportion of variation explained exclusively-independently of the other factors-by the individual host, for instance, was obtained with the following subtraction rule: $\mathrm{I}=(\mathrm{Ind}+$ Pop + Env $)-($ Pop + Env $)$; the proportions explained exclusively by the other factors were obtained in a similar way. The amount of variation attributable to the intersection of two factors (e.g., individual host and host population) was obtained with the subtraction rule: $\mathrm{IP}=($ Ind + Pop
+ Env) - Ind $-\mathrm{P}-\mathrm{E}$; where $\mathrm{P}$ is the explained variation by the pure effect of host population and $\mathrm{E}$ is the pure effect of environment. The amount of variation attributable to the intersections between individual and environmental factors (IE) and between population and environmental factors (PE) were calculated in a similar way, and the amount attributable to the intersections between the three factors together (IPE) was obtained with the subtraction rule: $\mathrm{IPE}=(\mathrm{Ind}+\mathrm{Pop}+\mathrm{Env})-\mathrm{E}-\mathrm{P}-\mathrm{I}-$ EP - IP - EI. Therefore, we determined a value for each part of deviance explained and knew how much corresponded to its pure effect and how much to intersections between two or three factors. This procedure was carried out on each of the three final models. The proportions of explained deviance for each factor were standardized to make them comparable among models; for this purpose they were expressed in relation to the proportion of deviance explained for the final model (e.g., Alzaga et al., 2009; Pérez-Ramírez et al., 2012).

Cross-validation is a procedure for assessing how the results of a statistical model can be generalized to an independent data set (Picard and Cook, 1984). Under our analytical design, we are interested in how the results of the model developed on the dataset for a given sex can be used to explain variation in the response variable on the dataset for another sex (validation dataset). Similarly, we assessed the performance of the model developed by combining data for males and hinds, which was calibrated using an 70\% random sample (training dataset) and was validated against the remaining $30 \%$ of the data (validation dataset). On each dataset and under this crossed framework, we binned predictions from the model into 10 evenly sized intervals of increasing predicted burdens. Assessment was carried out by plotting the mean observed against predicted abundance, in each interval on the validation datasets (see Pearce and Ferrier, 2000). The basic premise is that as the burdens predicted by the model increase (e.g., model for males), there should be a similar increase in the observed burdens in the validation dataset (in this case, on hinds dataset).

Statistical analyses were carried out in R 2.15.2 (R Core Team, 2012). The "MASS" library was used for model development (Venables and Ripley, 2002), the "HH" package for the VIF analyses (Heiberger, 2012), and the "ggplot2" package for the calibration plots (Wickham, 2009).

\section{RESULTS}

Tick data from 306 red deer-182 males and 124 females-were gathered for the 7 years of study (average deer no./year: 25.5; range: 12-64; Table 3). The 59.5\% (95\%CI: 54.0-65.0) of deer were parasitized by ticks, the major part only by adults $(59.2 \%$; 95\%CI: 53.7-64.7). Out of the 4009 ticks counted on deer, 1772 were collected (1761 adults and 11 nymphs). Adults belonged mainly to Hy. lusitanicum ( $n=1750 ; 98.8 \%)$, Rh. bursa $(n=9$; $0.5 \%)$, Rh. sanguineus ( $n=1 ; 0.05 \%)$, and Dermacentor marginatus $(n=1 ; 0.05 \%)$ and nymphs belonged to $H y$. lusitanicum $(n=9 ; 0.5 \%)$ and $R h$. bursa $(n=2 ; 0.1 \%)$. Annual average adult tick abundance per deer experienced a decrease along study years (Table 4).

Predictors included in the three final models are summarized in Table 5. VIFs obtained for the predictors included in final 
Table 3 | Data on the number of tick parasitized deer (PosT) with respect the total number (N) of analyzed deer throughout sex and age class.

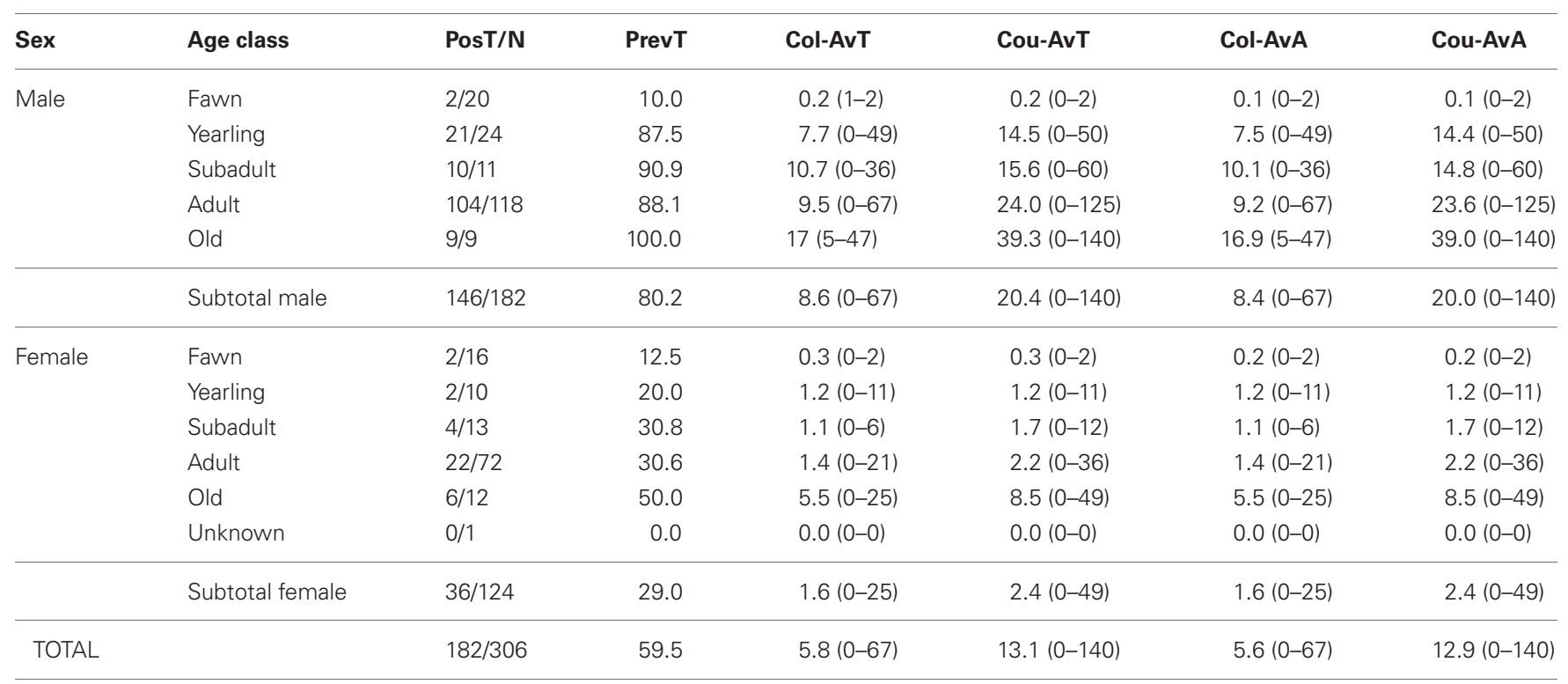

Average number of ticks/deer collected (Col_AvT) and counted (Cou_AvT) as well as collected (Col_AvA) and counted (Cou_AvA) adult ticks are displayed. Values within brackets represent minimum and maximum collected and counted ticks and adult ticks per deer. The female with unknown age was not considered for modeling purposes.

models showed that no biased predictions are expected due to collinearity-derived problems (VIFs $<2.21,<2.32$, and $<1.99$, for the model for males, for hinds, and for males and hinds, respectively). A higher amount of deviance was explained for the model of males (53.97\%) than for the other models $(46.26 \%$ and $50.76 \%$, for the model of hinds and the model of males and hinds, respectively). When data for males and females were considered in a model, "sex" was a relevant predictor and a significantly higher number of ticks was detected on males than on hinds (see also Table 3). The observed increasing tick burden with deer age was evidenced in both males and females (Table 5). Predictors related to the three considered factors (i.e., individual host, host population and environment) were selected for the three final models; but according to test-values, the relevance of the predictors varied among the models (Table 5).

Variation partitioning procedures showed that the amount of variation explained by the pure factors and the overlaid effects were quite different among the three models, mainly between the model for males and that for hinds (Figure 1). In the model for males, individual host and host population factors explained a higher amount of variation than in the model for hinds. For the hind model most of variation could be explained by the environmental factor. Finally, the model combining data from males and hinds showed an intermediate situation between the independent models for each sex, with a similar amount of variation explained by the host population factor than in the model of hinds, and a similar amount of variation explained by the environmental factor than in the model of males.

Finally, cross-validation showed that the independent models for each sex were not able to accurately explain the parasitization rate on the other sex (Figure 2). To this respect, the worst performance was obtained when the model for hinds was applied to the dataset of males (Figure 2A). The model for males precisely, but not accurately, explained tick parasitization on hinds, mainly for individuals with higher parasitization rates (Figure 2B); the model was precise because the observed abundance monotonically increased with predicted abundance (mainly for the higher intervals of predicted abundance), and it was not accurate because predictions overestimated the observed abundances. Finally, a model was adjusted by pooling data for males and females, and this model again overestimated the higher intervals of predicted abundance (Figure 2C). This combined model was closer to the response of males than to that of hinds.

\section{DISCUSSION}

Identification of factors driving tick parasitism on hosts has been a relevant issue in ecology (Moore and Wilson, 2002; Boyer et al., 2010; Calabrese et al., 2011), and is currently a relevant topic in tick-borne disease epidemiology (Perkins et al., 2003; Ruiz-Fons et al., 2012). Most studies have centered attention to small mammals (Brunner and Ostfeld, 2008; Alzaga et al., 2009; Boyer et al., 2010) and few attention has been paid to large mammals. Large mammals—such as red deerare key hosts for many epidemiologically relevant tick species (Ruiz-Fons and Gilbert, 2010; Ruiz-Fons et al., 2012), especially in Mediterranean environments (Ruiz-Fons et al., 2006). In south-central Spain, red deer are abundant (Acevedo et al., 2008) and have experienced a notable increase in the last three decades (Apollonio et al., 2010), which would have consequences for tick ecology and for zoonotic tick-borne pathogen epidemiology (e.g., Anaplasma phagocytophilum-(de la Fuente et al., 2005)—or Crimean-Congo haemorrhagic fever virusEstrada-Peña et al., 2013). Mating system (Miller et al., 2007), 
Table 4 | Average number of ticks/deer collected (Col_AvT) and counted (Cou_AvT) and average number of adult ticks/deer collected (Col_AvA) and counted (Cou_AvA) throughout year and season.

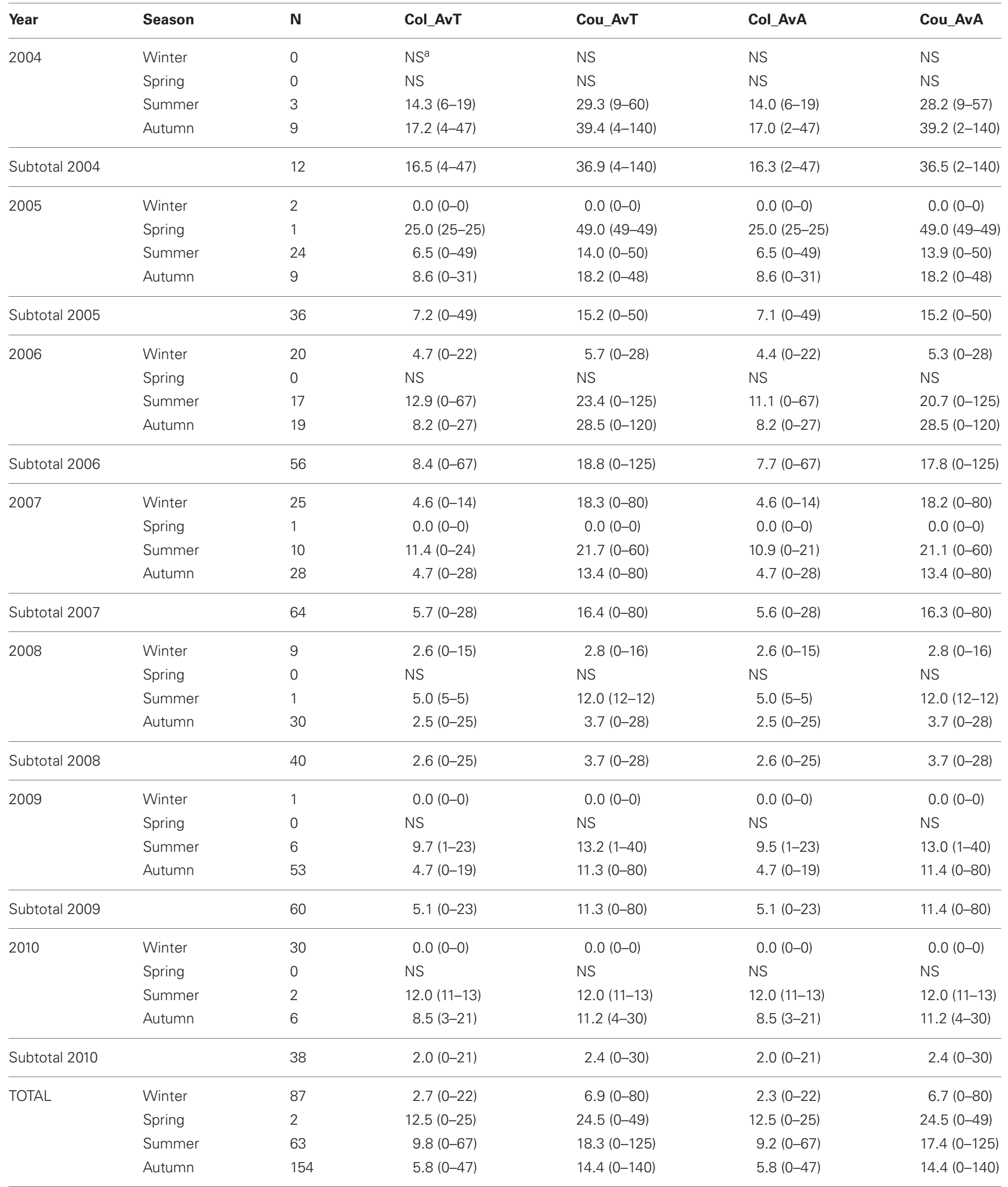

${ }^{a}$ NS, No samples. 
Table 5 | Statistical parameters (coefficient/test-value and significance: $n s:$ non-significant, $\# 0.1,{ }^{*} 0.05,{ }^{* *} 0.01$, and ${ }^{* * *} 0.001$ ) of the generalized lineal models (negative binomial error distribution and logarithmic link function) carried out to predict tick burden on red deer.

\begin{tabular}{|c|c|c|c|}
\hline Predictor (factor) & Model for males & Model for hinds & Model for males and hinds \\
\hline AvT_M (Env) & $0.0873 / 6.74 * * *$ & $0.1376 / 3.63^{* * *}$ & $0.0962 / 6.54 * * *$ \\
\hline Year (Env) & $-0.4869 /-7.16^{* * *}$ & & \\
\hline Deer_C (Pop) & $0.0158 / 5.94 * * *$ & & $0.0083 / 3.22 * *$ \\
\hline Deer_C t-2 (Pop) & & $0.0097 / 1.84 \#$ & \\
\hline KFI (Ind) & $-0.0033 /-3.19 * *$ & & $-0.0032 /-2.50^{*}$ \\
\hline AP_M (Env) & $-0.0067 /-2.49^{*}$ & $-0.0313 /-3.64 * * *$ & $-0.0189 /-6.47^{* * *}$ \\
\hline Wild boar_C t-2 (Pop) & & & $-0.0101 / 5.42 * * *$ \\
\hline Sex(females) (Ind) ${ }^{a}$ & & & $-1.5922^{\mathrm{a}} /-5.19 * * *$ \\
\hline Intercept & $965.5163 / 7.11 * * *$ & $-11.5223 /-2.77^{* *}$ & $-10.6220 /-6.35^{* * *}$ \\
\hline
\end{tabular}

Individual host (Ind), host population (Pop), and environmental (Env) factors; predictors coded as in Tables 1-2.

${ }^{a}$ Coefficient for females in relation to males.

A Individual host Host population

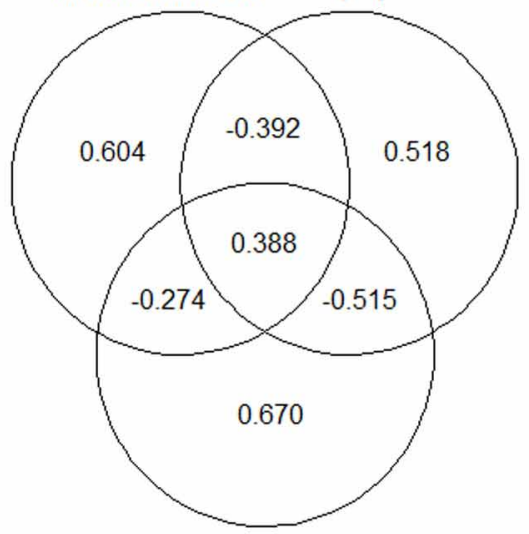

Environmental
B Individual host Host population

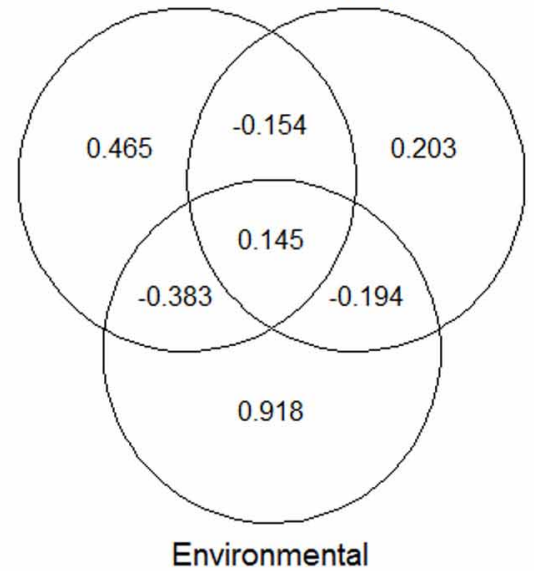

C Individual host Host population

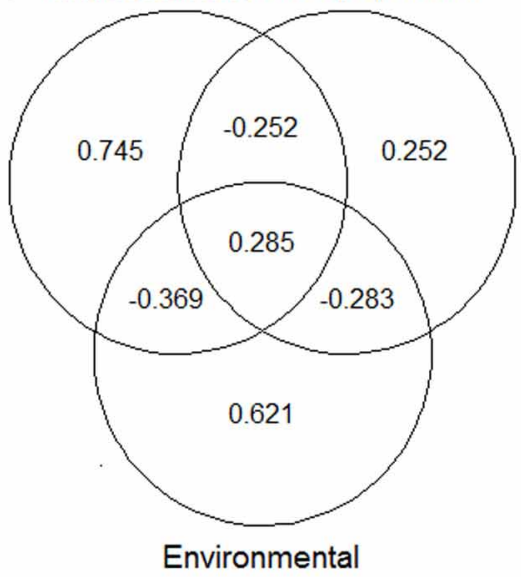

FIGURE 1 | Variation partitioning of the deviance explained by final models: (A) model for red deer males; (B) model for hinds; and (C) model for males and hinds. Values shown in the diagrams are the proportions of variation of each final model that can be explained exclusively by individual host, host population and environmental factors, and by the combined effect of these factors. See Table $\mathbf{5}$ for details about predictors included in each of the abovementioned models/factors. The "VarPart" function was used for producing the plots (Barbosa et al., 2013). 


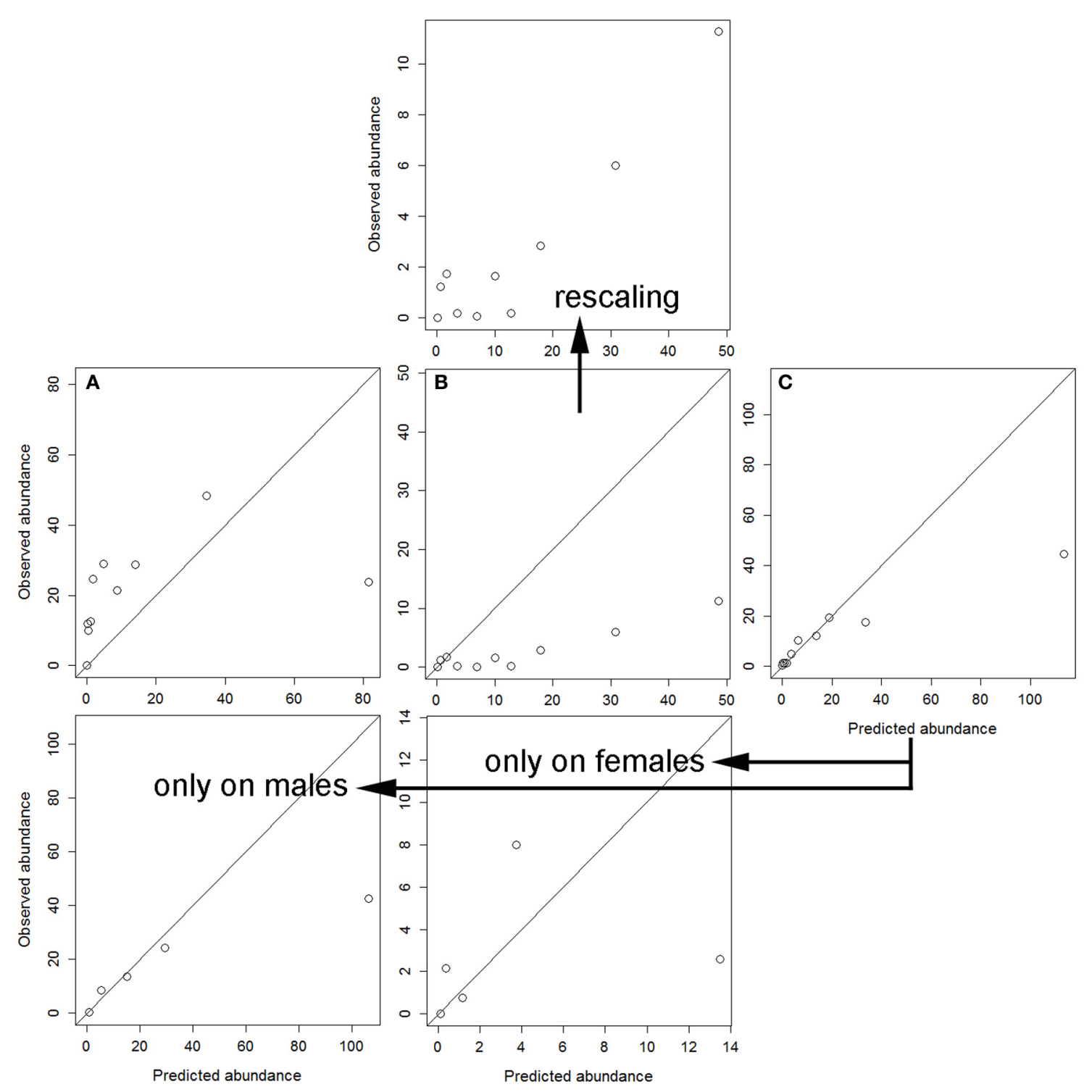

FIGURE 2 | Calibration's assessment of the three models (see Table 5) under a cross-validation procedure: (A) predictions from the model for hinds on the dataset for males; (B) predictions from the model for males on the dataset for hinds (also rescaling the observed

abundance axis); and (C) predictions from the model for males and hinds on the validation dataset, also independently for males and females (only five intervals were used in these last cases due to sample size).

sexual dimorphism (Moore and Wilson, 2002), intraspecific competition (Bacelar et al., 2011), space use (Boyer et al., 2010), testosterone levels (Hughes and Randolph, 2001), and even effects of environmental host-tick interactions (Calabrese et al., 2011), have been proposed as relevant factors driving sex-biased parasitism in mammals. Identifying factors driving tick-deer interactions at the individual level is thus a crucial issue for efficiently preventing and controlling tick-borne disease risks. In this study, deer males were evidenced as primary targets of exophilic ticks, mainly Hyalomma spp., and we showed that parasitism on each sex was differentially determined by host individual, host population and environmental factors.

\section{DIFFERENTIAL DRIVERS OF TICK PARASITISM IN MALES AND HINDS}

Even when tick burdens on males and hinds were modeled with the same set of predictors, each sex specific model was not able to accurately predict tick burdens on animals of the other sex (Figure 2). This cross-validation procedure allows us to suggest that tick burden in red deer are driven by different traits on males and hinds (see also Vicente et al., 2007a). In addition, the model for males was able to predict-with moderate precision, better for higher tick abundance-burdens on hinds. This was likely due to the over-dominance of the environmental factor in the model for hinds. Parasites benefit from situations in which hosts are not in good conditions (Murray et al., 1998). Variations in condition along the year in food supplemented populations are lower 
in hinds than in males (Santos et al., 2013; see also RodríguezHidalgo et al., 2010), since the latter are strongly affected by the rut period. Likely, this can be one of the reasons by which tick parasitism on males is more dependent on intrinsic factors that parasitism on hinds. Finally, the model combining data from males and females was better adjusted to variation in males than in hinds, evidencing again that parasitism in hinds is likely a simplification of the process in males.

Differential effects of host individual, host population and environmental factors in relation to the life cycle of parasites were evidenced in other mammal species (Alzaga et al., 2009). In European hare (Lepus europaeus), Alzaga et al. (2009) showed that the individual factor was the more explicative factor of tick burdens, followed by environmental and host population factors. In our study, we found relevant differences in the effects of each factor in relation to host sex, but in male and global models the effect of the individual factor was not clearly inferior to the others. Differences between the study on hares and the present study are likely related to the ecology of the host-tick system, i.e., ecological traits of host species but also of ticks, since different tick species were found parasitizing European hare and deer. In our study model, individual host and host population factors were more relevant for males than for hinds. In contrast, the environmental factor was more important explaining burdens on hinds. Potential reasons mediating these sex-biased differences are discussed below.

\section{HOST INDIVIDUAL FACTOR DRIVING TICK PARASITISM IN RED DEER}

Individual predictors such as size and age were positively related to tick abundance in red deer, while KFI was negatively related in the model for males. Size-measured by total length-and body mass were highly correlated in our data set (Spearman's rho $=$ 0.904, $p<0.001$ ), and consequently both influence tick burden in a positive proportional direction. Body size was selected as the most appropriate measure of animal's body surface exposed to questing ticks because body mass could be modulated by adlibitum availability of supplementary food. Similar results relating KFI and parasitism in males were obtained for red deer parasitized by Elaphostrongylus cervi in south-central Spain (Vicente et al., 2007b), suggesting a close relationship between KFI and macroparasite burden in red deer males in Mediterranean ecosystems. One trait responsible for this male-biased pattern in tick burdens could be related to resource allocation due to mating system, that can be also responsible for the higher relevance of the individual factor explaining tick burden on males than on hinds. This is coherent with results obtained for roe deer, in which sex-biased tick parasitism was only caused by a bias in male and female hunting seasons (Vor et al., 2010; Kiffner et al., 2011), a particular trait that did not account in our study where both sexes were surveyed in every season of the year. In contrast to roe deer males, red deer males defend big harems of several tens of females (Clutton-Brock et al., 1982). Keeping a higher number of hinds away from other males would make red deer males invest more resources in mating than those needed by roe deer males for the same purpose and this may be reflected in the immune system and finally on sexbiased parasitism in red deer males (Vicente et al., 2007b; Corbin et al., 2008). Likely, the apparent absence of any effect of KFI in the model for hinds could be related to the fact that KFI is significantly higher in hinds than in males and it remains constant throughout the year (Santos et al., 2013). Finally, the inverse relationship between KFI and tick burden in combination to the effect of body size, can explain the increasing trend on tick burden with host age.

Sex-related behavioral differences in the use of feeding and water points that could have led to differences in questing tick encounter rates by males and hinds, were discarded on the basis of a study on habitat selection of sympatric wild ungulates in the study estate (Sicilia, 2011). In this study, no sex-biased selection of feeders and water points were observed during summerwhen natural food and water are scarce in our territory. It was also observed that both sexes actively selected shrub nearby feeding and water points during daytime and accessed feeders from dusk to dawn, for which no sex-related differences in daily time spent in different habitats were evidenced. If deer spent most of their daily time in feeding and water points this would have been reflected by higher questing tick abundances in these points. However, data from a monthly year-round survey on questing ticks performed in the study hunting estate (F. Ruiz-Fons, unpublished data) showed that higher questing tick abundances are present in the ecotone between shrub and pasture and not in pasture surrounding feeding and water points, being these results coherent with those from habitat use studies (Sicilia, 2011).

Another individual trait that could rely behind male-biased tick parasitism is innate genetic resistance. Fernández-de-Mera et al. (2009a) — in the same study red deer population-found that red deer presenting major histocompatibility complex class II (MHC-II) DRB-2 haplotype 2 displayed significantly higher probability of being lowly parasitized by ticks with respect individuals displaying the other three most abundant $M H C-I I-D R B-2$ haplotypes in the estate. Data from a second study was reanalyzed for this study and showed that haplotype 2 was more frequent in hinds than in males (Fernández-de-Mera et al., 2009b), which could relate to the male-biased parasitism observed in our study. This hypothesis should be targeted in future experimental and field studies to properly identify its influence on male-biased tick parasitism.

\section{HOST POPULATION DENSITY DRIVING TICK PARASITISM IN RED DEER}

Density of hosts was selected in the independent models for each sex as related to tick burden, probably due to the fact that host densities regulate the percentage of adult ticks in the population that find a host and reproduce, thus contributing to densities of host-seeking ticks (Ruiz-Fons et al., 2012). Host population factor was able to explain a much higher amount of variation in the model for males than in the model for hinds. Likely these findings are again related to behavioral differences between sexes. Hinds live in groups and group size depends in a higher extent on antipredatory behavior-hunting resembles predation in our study population - than of the population density (Jedrzejewski et al., 2006), also in Mediterranean environments (Soriguer et al., 1994). Thus, population density may not be a key factor in determining tick transmission rates in hinds. In contrast, males are more solitary than females (Clutton-Brock et al., 1982), and the contacts in males should be closely dependent of the population density, mainly in the rut season (Carranza et al., 1996).

Wild boar are efficient hosts for Hyalomma spp. ticks (RuizFons et al., 2006), which was evidenced by the positive residual 
effect of wild boar counts two years prior to survey on tick burdens in both sexes. This residual effect could be perhaps related to the lower abundance of wild boar with respect red deer in the study hunting estate that would make wild boar not to be very relevant in maintaining questing tick abundance.

\section{ENVIRONMENTAL FACTOR DRIVING TICK PARASITISM IN RED DEER}

Environmental factor captured most of the variation explained in tick burdens in individual models, especially in hinds (Table 5; Figure 1). Climate modulates both tick activity and survival during their off-host period (Estrada-Peña et al., 2011; RuizFons et al., 2012) and modulates host-seeking tick abundance. Environmental tick abundance seems to be related to tick burdens in hinds and contribute together with host population and host individual traits to tick burdens in males (Table 5). The effect of climatic variables, with positive influences of average temperature and AET and negative influence of precipitation, may be related to the preponderance of the xerophilic Hy. lusitanicum in the study estate which peaks in late spring and early autumn when mean temperatures are high.

\section{FINAL STATEMENT}

The higher weight of host individual and host population factors in the model for males show that intrinsic deer factors

\section{REFERENCES}

Acevedo, P., Ruiz-Fons, F., Vicente, J., Reyes-García, A. R., Alzaga, V., and Gortázar, C. (2008). Estimating red deer abundance in a wide range of management situations in Mediterranean habitats. J. Zool. 276, 37-47. doi: 10.1111/j.14697998.2008.00464.x

Akaike, H. (1974). A new look at the statistical model identification. IEEE Trans. Automat. Contr. 19, 716-723.

Alzaga, V., Tizzani, P., Acevedo, P., Ruiz-Fons, F., Vicente, J., and Gortázar, C. (2009). Deviance partitioning of host factors affecting parasitization in the European brown hare (Lepus europaeus). Naturwiss 96, 1157-1168. doi: 10.1007/s00114-009-0577-y

Apanaskevich, D. A., and Horak, I. G. (2008). The genus Hyalomma Koch, 1844: V. Re-evaluation of the taxonomic rank of taxa comrpising the $H$. (Euhyalomma) marginatum Koch complex of species (Acari: Ixodidae) with redescritpion of all parasitic stages and notes on biology. Int. J. Acarol. 34, 13-42. doi: 10.1080/01647950808683704

Apanaskevich, D. A., Santos-Silva, M. M., and Horak, I. G. (2008). The genus Hyalomma Koch, 1844. IV. Redescription of all parasitic stages of $H$. (Euhyalomma) lusitanicum Koch, 1844 and the adults of $H$. (E.) franchinii Tonelli Rondelli, 1932 (Acari: Ixodidae) with a first description of its

are more efficient predictors of tick burden than environmental host-seeking tick abundance, at least when food availability is not a constraint. According to these results, controlling ticks in males such as acaricide spread on males through selective feeders or application of anti-tick vaccines to males only, would hypothetically result in a reduction of tick burdens in hinds since host-seeking tick abundance would be reduced significantly. Whether such an specific tick control measure on males would result in an immediate increase of tick burdens on hinds or in a substantial reduction should be specifically tested in the future.

\section{ACKNOWLEDGMENTS}

We are grateful to gamekeepers and Francisco Domínguez Sobrino for their help during field work. This study was supported by project AGL2010-20730-C02 (Spanish Ministry for Economy and Competitiveness) and EU FP7 grant ANTIGONE (278976). F. Ruiz-Fons is supported by a Juan de la Cierva contract from the Spanish Ministry for Economy and Competitiveness. P. Acevedo is funded from the SFRH/BPD/90320/2012 post-doctoral grant by Portuguese Fundação para a Ciência e a Tecnologia (FCT) and European Social Fund.

extended Poisson-gamma mixture model. PLoS ONE 6:e29215. doi: 10.1371/journal.pone.0029215

Cameron, A. C., and Trivedi, P. K. (1998). Regression Analysis of Count Data. Cambridge: Cambridge University Press. doi: 10.1017/CBO9780511814365

Carranza, J., Alarcos, S., SánchezPrieto, C. B., Valencia, J., and Mateos, C. (2004). Disposablesoma senescence mediated by sexual selection in an ungulate. Nature 432, 215-218. doi: 10.1038/nature03004

Carranza, J., Fernández-Llario, P., and Gomendio, M. (1996). Correlates of territoriality in rutting red deer. Ethology 102, 793-805. doi: 10.1111/j.14390310.1996.tb01201.x

Clutton-Brock, T. H., Guinness, F. E., and Albon, S. P. (1982). Red deer: Behaviour and Ecology of Two Sexes. Chicago, IL: University of Chicago Press.

Corbin, E., Vicente, J., MartínHernando, M. P., Acevedo, P., Pérez-Rodríguez, L., and Gortázar, C. (2008). Spleen mass as a measure of immune strength in mammals. Mammal Rev. 38, 108-115. doi: 10.1111/j.1365-2907.2007.00112.x

de la Fuente, J., Naranjo, V., Ruiz-Fons, F., Höfle, U., Fernández-de-Mera, I. G., Villanúa, D., et al. (2005). Potential vertebrate reservoir hosts and invertebrate vectors of Anaplasma marginale and
A. phagocytophilum in Central Spain. Vector Borne Zoonot. Dis. 4, 390-401.

Estrada-Peña, A., Bouattour, A., Camicas, J. L., and Walter, A. R. (2004). Ticks of Domestic Animals in the Mediterranean region. A Guide to Identification of Species. Zaragoza: University of Zaragoza Press.

Estrada-Peña, A., Martínez Avilés, M., and Muñoz Reoyo, M. J. (2011). A population model to describe the distribution and seasonal dynamics of the tick Hyalomma marginatum in the Mediterranean basin. Transbound. Emerg. Dis. 58, 213-223.

Estrada-Peña, A., Ruiz-Fons, F., Acevedo, P., Gortázar, C., and de la Fuente, J. (2013). Factors driving the circulation and possible expansion of Crimean-Congo haemorrhagic fever virus in the western Palearctic. J. Appl. Microbiol. 114, 278-286.

Fernández-de-Mera, I. G., Vicente, J., Naranjo, V., Fierro, Y., Garde, J. J., de la Fuente, J., et al. (2009a). Impact of major histocompatibility complex class II polymorphisms on Iberian red deer parasitism and life history traits. Infect. Genet. Evol. 9, 1232-1239.

Fernández-de-Mera, I. G., Vicente, J., Pérez de la Lastra, J. M., Mangold, A. J., Naranjo, V., Fierro, Y., et al. (2009b). Reduced major histocompatibility complex class II polymorphism in a hunter-managed isolated 
Iberian red deer population. J. Zool. 277, 157-170.

Folstad, I., and Karter, A. J. (1992). Parasites, bright males, and the immunocompetence handicap. Am. Nat. 139, 603-622. doi: $10.1086 / 285346$

Heiberger, R. M. (2012). HH: Statistical Analysis and Data Display: Heiberger and Holland. R Package Version 2.3-27. Available online at: http://CRAN.Rproject.org/package $=\mathrm{HH}$

Hughes, V. L., and Randolph, S. E. (2001). Testosterone depressed innate and acquired resistance to ticks in natural rodent hosts: a force for aggregated distributions of parasites. J. Parasitol. 87, 49-54.

Jedrzejewski, W., Spaedtke, H., Kamler, J. F., Jedrzejewska, B., and Stenkewitz, U. (2006). Group size dynamics of red deer in Białowieża primaveral forest, Poland. J. Wildl. Manage. 70, 1054-1059.

Kiffner, C., Lödige, C., Alings, M., Vor, T., and Rühe, F. (2011). Bodymass or sex-biased tick parasitism in roe deer (Capreolus capreolus). A GAMLSS approach. Med. Vet. Entomol. 25, 39-45.

Kiffner, C., Stanko, M., Morand, S., Khokhlova, I. S., Shenbrot, G. I., Laudisoit, A., et al. (2013). Sexbiased parasitism is not universal: evidence from rodent-flea associations from three biomes. Oecologia doi: $\quad 10.1007 / \mathrm{s} 00442-013-2664-1$. [Epub ahead of print].

Kitron, U., Jones, C. J., Bouseman, J. K., Nelson, J. A., and Baumgartner, D. L. (1992). Spatial analysis of the distribution of Ixodes dammini (Acari: Ixodidae) on white-tailed deer in Ogle County, Illinois. J. Med. Entomol. 29, 259-266.

Klevezal, G. A., and Kleinenberg, S. E. (1967). Age Determination of Mammals from Annual Layers in Teeth and Bones. Springfield: USSR Academy of Sciences. Translation by the Department of the Interior and National Science Foundation, US Department of Commerce.

Malo, A., Roldán, E. R. S., Garde, J. J., Soler, A. J., Vicente, J., Gortázar, C., et al. (2009). What does testosterone do for red deer males? Proc. Biol. Sci. 276, 971-980.

Manilla, G. (1998). Fauna d'ltalia. Acari: Ixodida. Bologna: Edizioni Calderini.

Miller, M. R., White, A., Wilson, K., and Boots, M. (2007). The population dynamical implications of male-biased parasitism in different mating systems. PLoS ONE 7:e624. doi: 10.1371/journal.pone.0000624

Moore, S. L., and Wilson, K. (2002). Parasites as a viability cost of sexual selection in natural populations of mammals. Science 297, 2015-2018. doi: $10.1126 /$ science. 1074196

Murray, D. L., Keith, L. B., and Cary, J. R. (1998). Do parasitism and nutritional status interact to affect production in snowshoe hares? Ecology 79, 1209-1222. doi: 10.1890/0012-9658(1998)079[1209: DPANSI]2.0.CO;2

Ostfeld, R. S., Canham, C. D., Oggenfuss, K., Winchcombe, R. J., and Keesing, F. (2006). Climate, deer, rodents, and acorns as determinants of variation in Lymedisease risk. PLoS Biol. 4:e145. doi: 10.1371/journal.pbio.0040145

Pearce, J., and Ferrier, S. (2000). Evaluating the predictive performance of habitat models developed using logistic regression. Ecol. Model. 133, 225-245. doi: 10.1016/S0304-3800(00)00322-7

Pérez-Ramírez, E., Acevedo, P., Allepuz, A., Gerrikagoitia, X., Alba, A., Busquest, N., et al. (2012). Ecological factors driving avian influenza virus dynamics in Spanish wetland ecosystems. PLoS ONE 7:e46418. doi: 10.1371/journal.pone.0046418

Perkins, S. E., Cattadori, I. M., Tagliapietra, V., Rizzoli, A. P., and Hudson, P. J. (2003). Empirical evidence for key hosts in persistence of a tick-borne disease. Int. J. Parasitol. 33, 909 .

Picard, R. R., and Cook, R. D. (1984). Cross-validation of regression models. J. Am. Stat. Assoc. 79, 575-583. doi: 10.1080/01621459.1984.10478083

R Core Team. (2012). R: A Language and Environment for Statistical Computing. Vienna: R Foundation for Statistical Computing. Available online at: http://www.R-project.org/

Rodríguez-Hidalgo, P., Gortázar, C., Tortosa, F. S., Rodríguez-Vigal, C., Fierro, Y., and Vicente, J. (2010). Effects of density, climate, and supplementary forage on body mass and pregnancy rates of female red deer in Spain. Oecologia 164, 389-398. doi: 10.1007/s00442-010-1663-8

Rolff, J. (2002). Bateman's principle and immunity. Proc. Biol. Sci. 269, 867-872.

Ruiz-Fons, F., Fernández-de-Mera, I. G., Acevedo, P., Gortázar, C., and de la Fuente, J. (2012). Factors driving the abundance of Ixodes ricinus ticks and the prevalence of zoonotic I. ricinus-borne pathogens in natural foci. Appl. Environ. Microbiol. 78, 2669-2676.

Ruiz-Fons, F., Fernández-de-Mera, I. G., Acevedo, P., Höfle, U., Vicente, J., de la Fuente, J., et al. (2006).
Ixodid ticks parasitizing Iberian red deer (Cervus elaphus hispanicus) and European wild boar (Sus scrofa) from Spain: geographical and temporal distribution. Vet. Parasitol. 140, 133-142.

Ruiz-Fons, F., and Gilbert, L. (2010). The role of deer as vehicles to move ticks, Ixodes ricinus, between contrasting habitats. Int. J. Parasitol. 40, 1013-1020.

Sáenz de Buruaga, M., Lucio, A. J., and Purroy, J. (1991). Reconocimiento de Sexo y Edad en Especies Cinegéticas. Vitoria: Diputación Foral de Álava Press.

Santos, J. P. V., Fernández-de-Mera, I. G., Acevedo, P., Boadella, M., Fierro, Y., Vicente, J., et al. (2013). Optimizing the sampling effort to evaluate body condition in ungulates: a case study on red deer. Ecol. Indic. 30, 65-71. doi: 10.1016/j.ecolind.2013.02.007

Schmidtmann, E. T., Carrol, J. F., and Watson, D. W. (1998). Attachmentsite patterns of adult blacklegged ticks (Acari: Ixodidae) on whitetailed deer and horses. J. Med. Entomol. 35, 59-63.

Schulze, T. L., Lakat, M. F., Bowen, G. S., Parkin, W. E., and Shisler, J. K. (1984). Ixodes dammini (Acari: Ixodidae) and other ixodid ticks collected from white-tailed deer in New Jersey, USA. 1. Geographical distribution and its relation to selected environmental and physical factors. J. Med. Entomol. 21, 741-749.

Shaw, D. J., and Dobson, A. P. (1995). Patterns of macroparasite abundance and aggregation in wildlife populations: a quantitative review. Parasitology 111, S111-S133.

Shaw, D. J., Grenfell, B. T., and Dobson, A. P. (1998). Patterns of macroparasite aggregation in wildlife host populations. Parasitology 117, 597-610. doi: 10.1017/S0031182098003448

Sicilia, M. (2011). Ecología y Comportamiento de Ungulados en Simpatría en un Ambiente Mediterráneo: Interacciones entre Especies Nativas y Exóticas de Interés Cinegético. Ciudad Real: Ph.D. thesis, University of CastillaLa Mancha. Available online at: https://www.educacion.gob.es/teseo/ imprimir Fichero Tesis. do ? fichero = 24536

Soriguer, R. C., Fandós, P., Bernáldez, E., and Delibes, J. R. (1994). El Ciervo en Andalucía. Sevilla: Junta de Andalucía Press.

Turc, L. (1954). Le bilan d'eau des sols. Relation entre la précipitation, l'évaporation et l'écoulement. Ann. Agron. 5, 491-569.
Venables, W. N., and Ripley, B. D. (2002). Modern applied Statistics with S. New York, NY: Springer. doi: 10.1007/978-0-387-21706-2

Vicente, J., Höfle, U., Fernández-deMera, I. G., and Gortázar, C. (2007a). The importance of parasite life history and host density in predicting the impact of infections in red deer. Oecologia 152, 655-664.

Vicente, J., Pérez-Rodríguez, L., and Gortázar, C. (2007b). Sex, age, spleen size and kidney fat of deer relative to infection intensities of the lungworm Elaphostrongylus cervi. Naturwiss 94 581-587.

Vicente, J., Höfle, U., Garrido, J. M., Fernández-de-Mera, I. G., Juste, R., Barral, M., et al. (2006). Wild boar and red deer display high prevalences of tuberculosis-like lesions in Spain. Vet. Res. 37, 107-119.

Vor, T., Kiffner, C., Hagedorn, P., Niedrig, M., and Rühe, F. (2010). Tick burden on European roe deer (Capreolus capreolus). Exp. Appl. Acarol. 51, 405-417. doi: 10.1007/s10493-010-9337-0

Wickham, H. (2009). Ggplot2: Elegant Graphics for Data Analysis. New York, NY: Springer.

Zuur, A. F., Ieno, E. N., and Elphick, C. S. (2010). A protocol for data exploration to avoid common statistical problems. Methods Ecol. Evol. 1, 3-14. doi: 10.1111/j.2041210X.2009.00001.x

Conflict of Interest Statement: The authors declare that the research was conducted in the absence of any commercial or financial relationships that could be construed as a potential conflict of interest.

Received: 27 April 2013; accepted: 09 June 2013; published online: 27 June 2013.

Citation: Ruiz-Fons F, Acevedo P, Sobrino $R$, Vicente J, Fierro $Y$ and Fernández-de-Mera IG (2013) Sexbiased differences in the effects of host individual, host population and environmental traits driving tick parasitism in red deer. Front. Cell. Infect. Microbiol. 3:23. doi: 10.3389/fcimb.2013.00023 Copyright (c) 2013 Ruiz-Fons, Acevedo, Sobrino, Vicente, Fierro and Fernándezde-Mera. This is an open-access article distributed under the terms of the Creative Commons Attribution License, which permits use, distribution and reproduction in other forums, provided the original authors and source are credited and subject to any copyright notices concerning any third-party graphics etc. 


\section{APPENDIX}

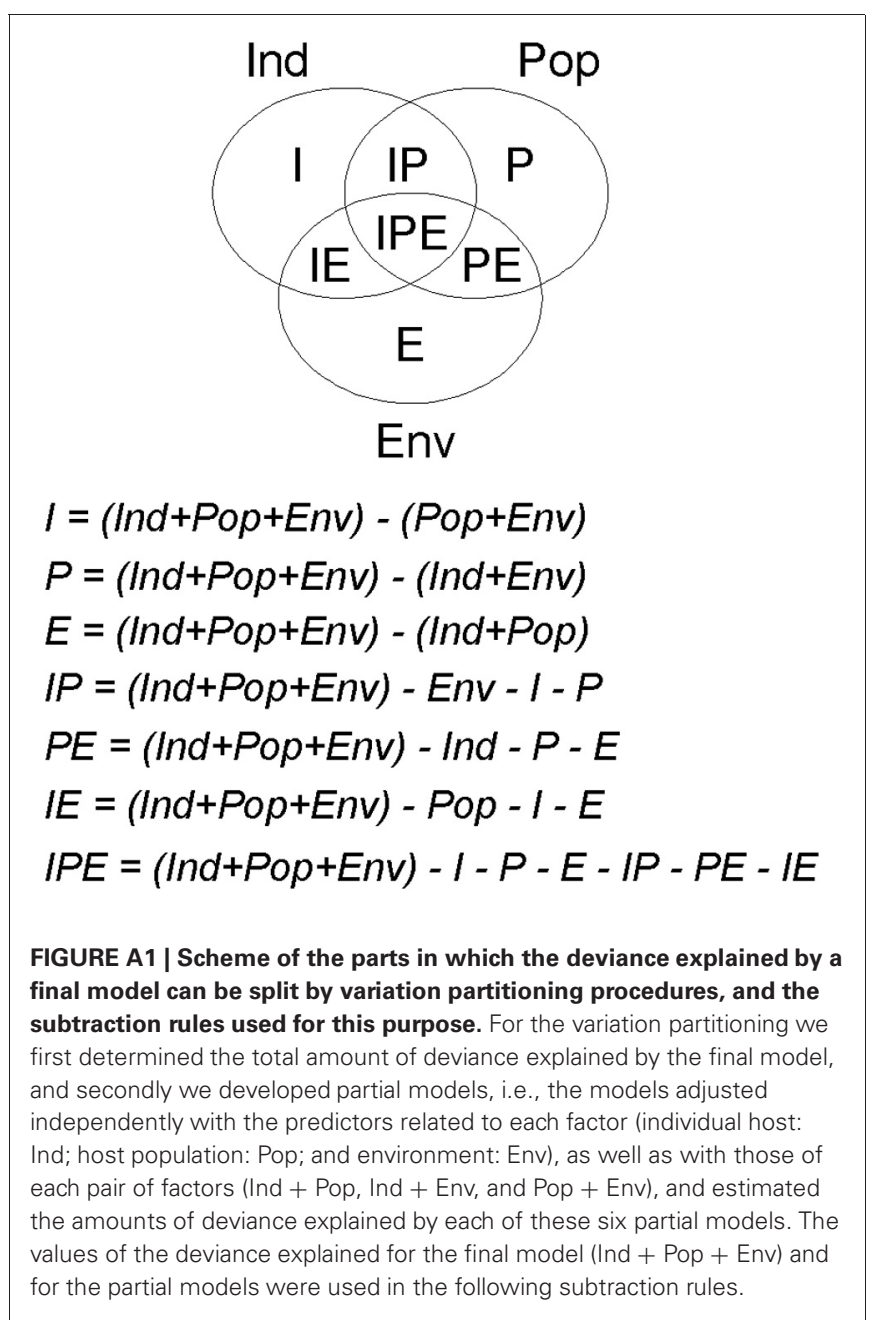

